The Buckingham Journal of Language and Linguistics 2015 Volume 8 pp 1-20

\title{
FINAL-NASAL DELETION IN AKAN (ASANTE TWI) REDUPLICATION
}

\author{
Kwasi Adomako \\ University of Education, Winneba \\ Ghana \\ myadomako@yahoo.com
}

\begin{abstract}
In this paper, I examine the phenomenon of reduplicant-nasal deletion observed in some reduplicative prefixes of Akan (a Niger-Congo, Kwa language). In the Akan phonology, nasals are among non-vowel sonorants that are permitted syllable or word-finally (Dolphyne 1988, Abakah 2005). However, it is observed that these nasals, particularly [m], are sometimes deleted in some reduplicants final position. In this paper, I show that verb bases of CVN or CVVN structures are of two different morphemic structures in the underlying representation; monomorphemic verb base and bimorphemic verb base. The latter structure, on which this paper focuses, has the composition: morpheme ${ }_{1}+$ morpheme $_{2}$. It is observed that while the former preserve their 'final' nasals in the reduplicants, the latter, on the other hand, lose them in their reduplicants. We analyse this phonological phenomenon as resulting from the language's bid towards satisfying a high-ranking template satisfaction constraint (after McCarthy and Prince 1994) within the Optimality Theory framework.
\end{abstract}

Keywords: Nasal deletion, Akan, reduplication, Optimality Theory, phonology.

\section{INTRODUCTION}

This paper examines the process of reduplicant-final bilabial nasal deletion in reduplication of some verb bases of Asante Twi (henceforth, Asante), a dialect of Akan, a member of Kwa, Niger Congo language. Reduplication as a phenomenon has received some appreciable body of research in the fields of both phonology and morphology in particular. Reduplication, in general, has been an area of research interest over the past centuries cross-linguistically, and its study in the Akan language could be traced back to the $19^{\text {th }}$ century with the pioneering work by Christaller in 1875. Since then, there have been quite a number of works on this subject in the language by a number of linguists including Welmers (1946), Schachter and Fromkin (1968), Wilbur (1973abc), Marantz (1982), Dolphyne (1988), 
McCarthy and Prince (1994, 1995, 1997), Raimy (2000), Abakah (2004, 2015), among others. It has contributed a lot to the field of phonology especially as it argues that certain types of precedence structures are manifested only in reduplication and as a result of this, some linguists have dubbed reduplication as the "microcosm of phonology" (Raimy 2000). Judging from the important role reduplication plays in our understanding of phonology in general, this paper aims to contribute, in a way, to our knowledge of the subject in particular and phonology in general.

In reduplicating verbal bases in Akan, the reduplicants usually undergo some phonological processes including syllable structure reduction, vowel raising, tonal changes, etc. These phonological processes have been discussed by the various authors on Akan reduplication. However, there is one syllable structure reduction phenomenon which has not yet caught the attention of these authors that this paper seeks to examine. This phenomenon is the reduplicant-final nasal deletion. It is observed about reduplication in Akan that sometimes a verbal base-final bilabial nasal deletes in the reduplicant, while at another time it does not. In this paper, we categorise the base with the final bilabial nasal into two; monomorphemic base and bimorphemic base. We observe that while the final bilabial nasal is in inherent in former base, it belongs to the second morpheme (i.e. a postposition) of the phrasal verb base in the latter. While the former case can be straightforwardly accounted for, I account for the reduplicant-final $/ \mathrm{m} /$ deletion within the Optimality Theory (henceforth, OT) by explaining that there is a templatic requirement imposed on size of the reduplicant. This leads to the blocking of the morpheme ${ }_{2}$ from surfacing, though it is a composite member of the base in the reduplication of bimorphemic base verbs.

This rest of the paper is organized as follows: Section 1 discusses the generalizations about the syllable structure as well as the morpheme-final nasals of Akan. In section 2, I discuss what other scholars have said about reduplication. In the same section, I present the Akan data on reduplication and make generalizations about these data thereof. These data are then formalised within the Optimality Theory framework in the same section. Section 3 concludes and summarises all the discussions made in this paper.

\section{THE AKAN SYLLABLE STRUCTURE}

Akan is noted to be among the languages that mostly prefer open syllables to closed ones. This syllable structure prominently manifests itself in its verbs in particular, which have CV syllable structure. According to Dolphyne (1988:52), the syllable in Akan is also described in terms of the tone on which the consonant and/or vowel which make up the syllable is uttered. Also, it is only syllabic consonants, which are tone-bearing units that are permitted word-finally in Akan aside from vowels. We illustrate this in (1) examples of which are adapted from Dolphyne (1988:53-54). 


$\begin{array}{llll}\text { N.CV } & \text { n.su } & \text { water } & * \mathrm{NCV} \\ \text { CV.N } & \text { so.m } & \text { hold it } & * \text { CVN }\end{array}$

It is worth noting that not all nasals that we find in the surface representation of the language are syllabic. All nasal consonants at the onset of syllables are not syllabic. Dolphyne (1988) further postulates that each vowel in Akan constitutes a syllable on its own. Therefore, in the context of a sequence of two vowels of the same or different qualities, each belongs to a different syllable. Therefore, the following words are represented in the syllable structure in (2).

$$
\begin{array}{lccc}
\text { CV.V } & \text { ti.e } & \text { listen } & * \mathrm{CVV} \\
\text { CV.V } & \text { mI.I } & \text { be full/eat enough } & * \mathrm{CVV}
\end{array}
$$

Based on the claims made above, syllable structures such as *CVC, *VC, *CCV, ${ }^{*} \mathrm{CVV},{ }^{*} \mathrm{CVVC}$, etc. do not exist in Akan.

\section{SYLLABLE/MORPHEME-FINAL NASALS IN AKAN}

Abakah (2005) argues about the coda in Akan syllable structure that there can never be a word or syllable with final consonant (obstruent) and posits that;

there is no morpheme in Akan that is consonant-final at the systematic phonemic level and, for this reason, any analysis that posits an underlying consonant as a morpheme-final consonant starts on a faulty note (Abakah 2005:53).

He further argues that it is only [+sonorant] consonants such as nasals, labio-velar glide, and liquids can occur word-finally in the surface representation in Akan. Therefore, there cannot be any syllable of $\mathrm{C}_{1} \mathrm{VC}_{2}$ structure in Akan in which $\mathrm{C}_{2}$ is a [-sonorant] segment. In furtherance of his argument, he posits that the $/ \mathrm{N} /$ has two realizations. This was a direct response to Schachter and Fromkin's (1968) claim about the underlying finals stops in Akan. While the underlying bilabial nasal stop surfaces as [m] in all the three dialects, the underlying alveolar nasal becomes in [n] in the Fante dialect, $[\mathrm{y}]$ in the Akuapem dialect, but replaced with a high vowel in the Asante dialect depending on the roundness of the stem vowel. This is further illustrated in (3) and (4) respectively. On the final alveolar nasal realisation in the Asante dialect, Abakah continues that the intervocalic alveolar nasal is deleted in Asante and they are replaced with [+high] vowels depending on the ATR value of the stem and roundness of the stem vowel in the surface representation. He further argues that the deleted nasal spreads its nasal 
feature to the epenthesized vowel before it deletes. Therefore, for instance, an epenthesized high front vowel /i/, will thus become /î/ as in (3).

Concluding his views on word-final sonorants, especially the nasals, Abakah (2005) suggests that they are non-final in the underlying representations and they become word-final in the surface representations when they precede [+high] vowels, which delete in the surface representations in the Fante and the Akuapem dialects as in (3). But for the alveolar nasal in the Asante dialect, it is the intervocalic nasal that deletes as in example under Asante in (3). (Data in (3) and (4) are adapted from Abakah, 2005:49).

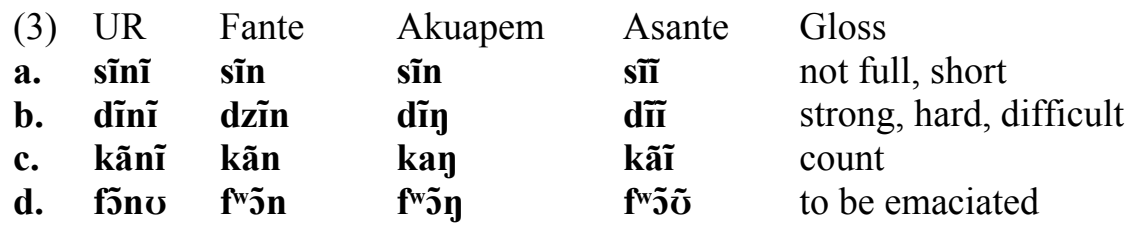

The bilabial nasal is the same in all the three major dialects of Akan as follows in (4). Let us note that the underlying forms are monomorphemic, i.e. each composes of a single morpheme/root.

$\begin{array}{llllll}\text { (4) } & \text { UR } & \text { Fante } & \text { Akuapem } & \text { Asante } & \text { Gloss } \\ \text { a. } & \text { pãmo } & \text { pãm } & \text { pãm } & \text { pãm } & \text { sew } \\ \text { b. } & \text { tãmo } & \text { tãm } & \text { tãm } & \text { tãm } & \text { lift } \\ \text { c. } & \text { pĩmo } & \text { pĩm } & \text { pĩm } & \text { pĩm } & \text { to head-butt, crash into } \\ \text { d. } & \text { bãmo } & \text { bãm } & \text { bãm } & \text { bãm } & \text { embrace somebody }\end{array}$

In addition to the nasals, both labio-velar glide $/ \mathrm{w} /$ and the liquid $/ \mathrm{r} / \mathrm{can}$ occur word-finally in the surface representation under the same condition as the bilabial nasal in the Fante dialect, while only the former segment is permitted in the same position in the Akuapem dialect ${ }^{1}$.

\section{GENERALISATIONS ABOUT AKAN SYLLABLE STRUCTURE}

In Akan, it is observed that all syllables that appear as closed forms (with underlying $\mathrm{CV}_{1} \mathrm{~N}, \mathrm{CV}_{1} \mathrm{~V}_{2} \mathrm{~N}$ structures, where $\mathrm{V}_{1}$ is specified [+high]) lose their final nasals in the reduplicant at the surface level of representation. These verb bases with final nasals in the base usually employ nasals as their nominal prefix during nominalization processes. We treat this phenomenon in this paper as an instance of the emergence of the unmarked in Akan reduplication (following McCarthy and Prince, 1994). This stems from the fact that it is the unmarked open syllable, in terms of syllable closure, which

${ }^{1}$ For detailed discussions of this syllable or morpheme-final consonants, please refer to Dolphyne (1988), Eshun (1993) and Abakah (2005). 


\section{VOLUME 8}

emerges in their reduplicants, though the closed reduplicant (i.e. with final nasal) would not have been dispreferred by the general grammar on any grounds. The bilabial nasal is the most common among nonvowel sonorants such as $/ \mathrm{m}, \mathrm{n}, \mathrm{w}$, and $\mathrm{r} /$ permitted word-finally in Akan (Dolphyne 1988, Abakah 2005). It is mostly some particular base forms of the syllable structures CVN, CVVN that are affected by this deletion process. In this paper, I offer explanation for this phenomenon as follows.

First, one possible explanation for this deletion process is that, because the base-final nasal, which is syllabic, lacks a nucleus, thereby making it vulnerable to deletion in the course of reduplication. We hypothesize in this paper that the same deleted nasal segment lingers on and later resurfaces in the nominalization process as the nominal prefix (as exemplified in (1)), perhaps to compensate for the loss in the reduplicant. We make this claim based on the observation that the reduplicated verbs that maintain their syllable weight/size in the reduplicant select for front low vowels, instead of nasals, as their nominal prefixes. A second possible explanation is that all the affected base forms are underlyingly bimorphemic in composition. Therefore, what we see as a deletion of just a segment $/ \mathrm{N} /{ }^{2}$ in the phonetic representation may rather be a deletion of an underlying separate morpheme of NV syllable structure as in $/ \mathbf{m u} /$. A third and final possibility which this paper will analyse in detail in section 4 will be offered within the OT framework. It would be explained that the reduplicant-final nasal deletion results from a high-ranking of some template satisfaction requirement constraint that bars the reduplicant from copying more than one lexical item or morpheme. What this presupposes is that any candidate that faithfully copies the base will fatally violate this high-ranking markedness constraint in tableau analysis.

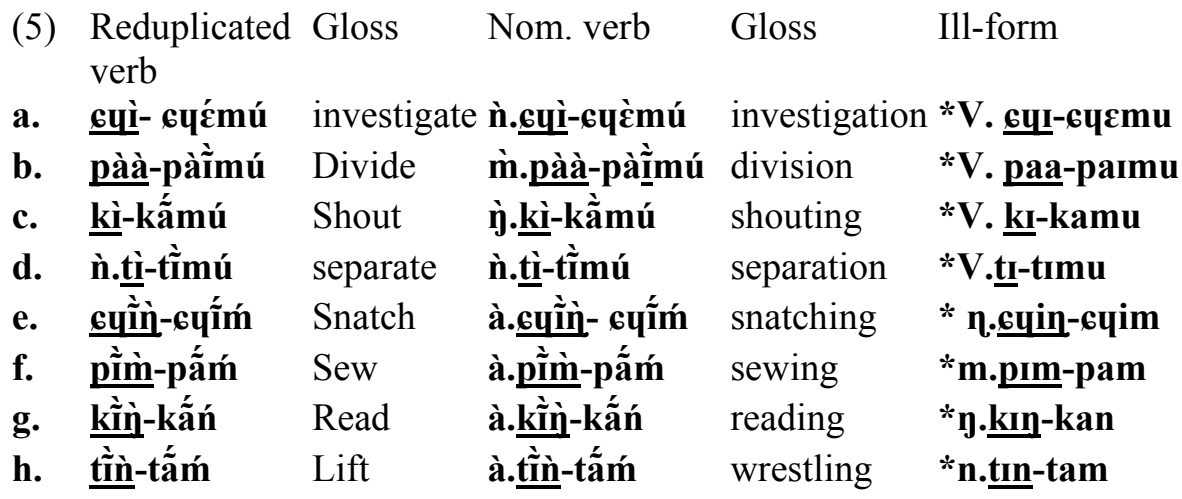

\footnotetext{
${ }^{2}$ The archiphoneme /N/ used here represents a homorganic nasal which in the present discussion it is restricted to the bilabial nasal $[\mathrm{m}]$ since it is the only nasal that among all the three major dialects of Akan (viz. Asante, Akuapem, and Fante) resists any phonological rules that the other nasals undergo in final position.
} 
In (5), I provide data on how bimorphemic nasal-final verbs are nominalised in Akan to illustrate the points made earlier above about the resurfacing of the 'lost' reduplicant-final bilabial nasal.

We make generalisation about the reduplication pattern observed in (5) as follows;

When nominalising reduplicated verbs, the homorganic nasal is employed as the nominal prefix (5a)-(5d), when the reduplicant-final bilabial nasal deleted, otherwise, a vowel is employed as the nominal prefix as in $(5 \mathrm{e})-(5 \mathrm{~h})^{3}$.

\section{REDUPLICATION}

Raimy (2000) loosely defines reduplication as the repetition of a sequence of segments. He continues to postulate that the analysis of the phenomenon should contribute knowledge to both phonology and morphology and that the neglect of either of the two modules of grammar will serve as a setback to the completeness of the outcome of such analysis. He argues that explanations of reduplication processes emanate "from phonological structures which are created in morphology and interpreted by phonology".

On their part, McCarthy and Prince (1995) define reduplication in terms of identity; whereby the reduplicant copies the base. They continue that there may always not be perfect identity between the base and the reduplicant because of templatic requirements. They postulate that attaining reduplicative identity may sometimes lead to disruption of certain phonological processes. In the quest for identity-preserving interaction between phonology and reduplication, some expected phonological processes may either fail to apply or underapply or they may overapply. They explain the term overapplication to refer to a situation whereby there is a disparity between the output and the lexical item that is not phonologically-grounded. Conversely, they explain the term underapplication as the situation where there is a 'lack an expected disparity between the input stem and the output' (cf. McCarthy and Prince 1995:2). A common example they cite to explain the latter phenomenon is the Akan example whereby palatalization fails to apply in the reduplicant when such failure lacks phonological motivation. Since the latter phenomenon falls within the main focus of this paper, much of the attention will be devoted to this discussion for the rest of the paper. I will further elaborate this point after I present data in Akan in section 3.

\footnotetext{
${ }^{3}$ It is worth noting at this point that it is not only the low vowel that can be used as nominal prefix in Akan apart from the nasals. All the mid vowels in Akan viz /e, $\varepsilon, o$, o/ can be used as nominal prefixes sometimes depending on how they harmonise with the stem vowels in terms of ATRness, hence, our representation of the nominal prefix with $\mathrm{V}$ which stands for any vowel of any quality (with the exception of high vowels).
} 


\section{VOLUME 8}

Kager (1999:194) on his part also initially describes reduplication from a purely morphological point of view as a kind of affixation, both in its morphosyntactic contribution and in its linear position with respect to the stem. But from a phonological perspective, he defines it as a phenomenon, which involves phonological identity between the reduplicant and the base to which the former adjoins.

The study of Akan reduplication has received an appreciable scholarly research over the decades with works by Schachter and Fromkin (1968), Marantz (1982), Dolphyne (1988), Abakah (2004, 2015) Ofori (2013), among others. All these works, in one way or another, have studied the subject from different, but related perspectives. However, none of the above mentioned literature has as yet discussed the behaviour or pattern of the underlying initial nasal consonant of the second morpheme (morpheme ${ }_{2}$ ) of bimorphemic bases when reduplicated. This current study intends to fill the vacuum left in the study of reduplication by investigating how this nasal deletes in the reduplicant. It also attempts to provide comprehensive account of this targeted phonological process in OT.

\section{AKAN REDUPLICATION: DATA AND GENERALISATIONS}

As Dolphyne (1988) claims, every Akan verb is potentially reduplicative, but unlike the previous literature on Akan reduplication so far mentioned that lump analyses of reduplication of different Akan word categories/classes in a discussion, the current paper specifically focuses on verb bases that have final nasal consonants. Our expressed interest in the bilabial nasal is motivated by the fact it is the only place of articulation among nasal stops that survives any form of alternation resulting from deletion rules in the general grammar of the three dialects of the Akan language as seen in (5). We further illustrate this realisation in reduplicated forms in (6). All reduplicated forms discussed in this paper are in their habitual mood construction. In this section, we first discuss reduplication of monomorphemic verb bases in $\S 1.2$ and reduplication of bimorphemic verb bases in $\S 1.3$. We conclude our discussions in this section with brief comments on this final bilabial nasal deletion phenomenon in $\S 1.4$.

\subsection{MONOMORPHEMIC BASE REDUPLICATION}

In reduplicating monomorphemic verb bases, the reduplicant copies the entire base including the base-final nasal stops which are inherently part of the base. Therefore, any attempt to reduce the size of the reduplicant will result in ungrammaticality as evident in the output forms to the extreme right column in (6). 


\begin{tabular}{|c|c|c|c|c|}
\hline (6) & Base & Reduplication & Gloss & N-deletion \\
\hline a. & cyán & cî̀ǹ-6पáń & dislocate & * çî̀-cuáń \\
\hline b. & kấń & kî̀ǹ-kấń & read & * $\underline{\mathbf{k i ̂ ̀}}-\mathbf{k}$ ã́ń \\
\hline c. & tấḿ & tî̀n-tấm & pick up & * tî̀-tấm \\
\hline d. & hấḿ & hî̀ǹ-hã́ḿ & to hold one's breath & *hî̀-hấḿ \\
\hline e. & dzấḿ & dzồn-ddấm & slap (in the face) & * d doìn-dzấm \\
\hline f. & tcyấḿ & tcuĩ̀ñ-tcyấm & wither & * tcuĩ̀-tcuấm \\
\hline g. & 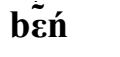 & bî̀m-béśn & get close to & 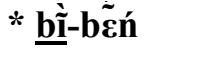 \\
\hline h. & pî́m & pî̀m-pî́ḿ & crash into/collide & * pĩ̀-pî́ḿ \\
\hline i. & cyî́ḿ & cपî̀ǹ-сبî́ḿ & snatch & * uĩ̀-сبî́ḿ \\
\hline j. & kũḿ & kĩ்̀̀-kṹn & kill & * k kũù-kũú \\
\hline
\end{tabular}

Based on the examples in (6), we can postulate the following generalisation about how the reduplicant surfaces when reduplicating CVN base forms. We state this generalisation as follows in (7).

(7) When reduplicating a base form with final nasals: Copy the entire base into the reduplicant slot.

In (6), we observed that the reduplicant completely copies all the segments in the base. The only mismatch between the bases and the reduplicants is the variation in their vocalic height. This raising process has been termed in the literature as a-raising. This simply refers to the process whereby a base vowel which is specified as [+low] raises to a [+high] vowel in the reduplicant ${ }^{4}$. It is not only stem low vowel that is prone to height raising, stem mid vowels can also raise in reduplicants as seen in (6vii).

\subsection{BIMORPHEMIC BASE REDUPLICATION}

For the bimorphemic base forms in this section, it is crucial to first establish what the actual composite of those forms is in the underlying representation. This will help shed light, to some extent, on why the reduplicant does not surface with the base-final nasal at the phonetic level of representation. Here, we will observe that unlike in the previous examples, the base-final (specifically bilabial) nasal deletes in the reduplicant.

Given our prior knowledge that a bilabial nasal invariably surfaces in the general grammar of Akan, it becomes expedient we establish what the variation is between the underlyingly monomorphemic forms as discussed in

${ }^{4}$ For detailed discussion of this raising pattern in Akan reduplication, please see Adomako (2012), among others. 


\section{VOLUME 8}

(6) and their symmetrically bimorphemic counterparts in the phonemic representation. In (8), the morpheme 2 ; $m u$, which is a locative marker, is a component of a phrasal verb and is translated as 'inside'. Morpheme ${ }_{1}$, which is the main verb, is the head of the reduplicated verb.

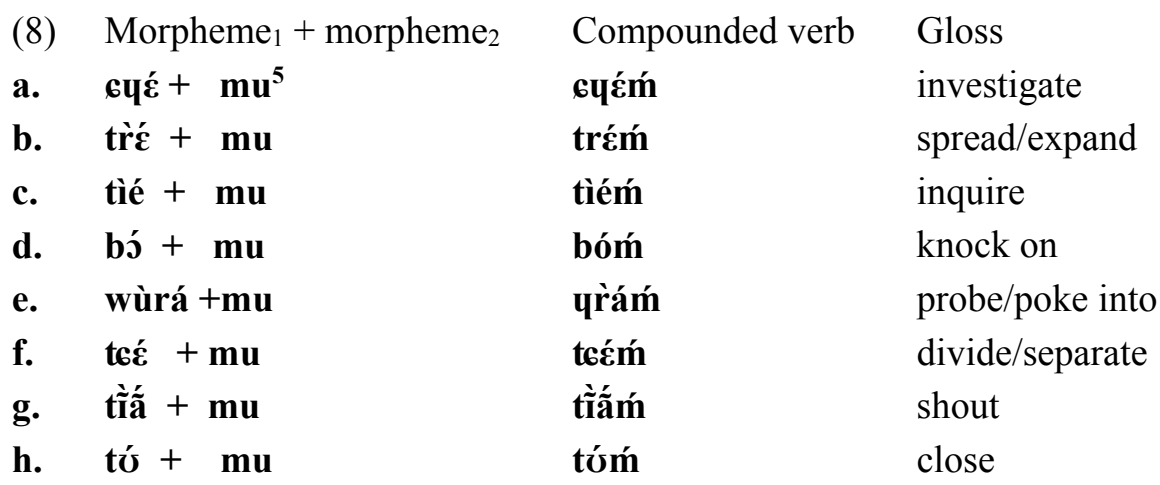

We postulate the phonological rule in (9) based on the above examples in (8). From the generalisation in (9), when the reduplicant copies the entire base (with the final nasal), it results in ill-formedness.

(9) When reduplicating an underlying two-morpheme stem: Delete the entire second morpheme in the reduplicant.

\begin{tabular}{|c|c|c|c|}
\hline $\begin{array}{l}\text { (10) } \\
\text { a. }\end{array}$ & $\begin{array}{l}\text { Compounded verb } \\
\text { cuśḿ }\end{array}$ & $\begin{array}{l}\text { Reduplicated } \\
\text { cyì-cý́ḿ }\end{array}$ & $\begin{array}{l}\text { Gloss } \\
\text { investigate }\end{array}$ \\
\hline b. & tr̀éǵm & trè-tr̀éḿ & spread/expand \\
\hline c. & tìém & tìé-tiéḿ & listen attentively \\
\hline d. & tcé́ń & tcì-tcéḿ & divide/separate \\
\hline e. & tĩ̀à̀ḿ & 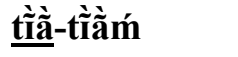 & Shout \\
\hline f. & tờm & tò̀-tờm & close \\
\hline g. & sã́m & sì-sấḿ & select \\
\hline h. & h. tcriéḿ & tç⿳亠丷厂́-tcriéḿ & explain \\
\hline i. & dyìám & dyiéé-dyì̀mḿ & enquire \\
\hline i & pã̀ì̀ḿn & pàà-pã̀ì̀m & break into parts \\
\hline k. & d女yớm & d & to relax something \\
\hline 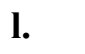 & dzà̀̀ìńm & d_èè-dzầî̀m & to let loose \\
\hline
\end{tabular}

${ }^{5}$ The second morpheme $/ \mathrm{mu} /$ functions syntactically as a locative marker which is loosely glossed "inside (of something)". 
Let us note again that nasalisation fails to apply in the forms with oral vowels in the underlying representation as in (8a) - (8d), but it duly applies in the forms in (8e) - (8h) which inherently have nasal vowels.

We have just seen that in reduplicating monomorphemic verbs, the morpheme-final bilabial nasal surfaces in the reduplicant, which we have seen that it is not the case with reduplicating bimorphemic verbs that end in bilabial nasal. We provide more examples of the latter in (10).

Now having seen the compounded verbs, it is expedient we establish how the bimorphemic verbs are derived as input forms for reduplication.

\subsection{COMMENTS ON THE REDUPLICANT-FINAL [M] DELETION}

There are phrasal verbs such as $\mathbf{6 4} \boldsymbol{\varepsilon}+\mathbf{s o}$ 'look on', 6y $\boldsymbol{\varepsilon}+$ ntcen 'look besides', 64ع + to 'look at the back/end' etc. but none of these verbs do encliticize as $\mathrm{V}+\mathrm{mu}$ which is the focus of discuss of this current paper. Therefore, we can postulate two input forms of phrasal verbs for reduplication;

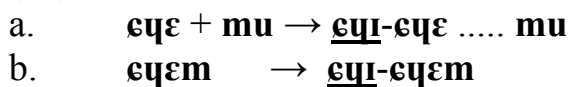

These encliticised forms do not manifest themselves only in the phonetic level of representation, but also synchronically, in the writing system or orthography of Akan. This is where the problem would be posed to the first language acquirer or even a second language learner who would not be able to differentiate between which input verbal form is monomorphemic and which one is bimorphemic in the underlying representation. A primary objective of the discussion of this paper is to show that there can be two forms of verbs that exhibit final bilabial nasal in the surface representation. One is monomorphemic and the other is bimorphemic i.e. encliticised form of a phrasal verb. The latter, which discussions in this paper have primarily focused on, has the underlying structure; verb + postposition.

We analyse this [m] deletion in the reduplicants of the bimorphemic bases as an instance of the emergence of the unmarked in the following summarised assumptions.

The first assumption is that the closed verb bases CVN/CVVN are realized as open syllable $\mathrm{CV} / \mathrm{CV} . \mathrm{V}$ in the reduplicant; the structure in the reduplicant is the universally unmarked structure in terms of syllable closure. Therefore, we can claim that there is the emergence of the unmarked syllable structure in the reduplicant in this context. 


\section{VOLUME 8}

Second, since the bilabial nasal has been shown to be the only nasal that is allowed word-finally in all the three major dialects of Akan (cf. Abakah, 2005), its deletion in the bimorphemic reduplicant is phonologically unmotivated. We may account for this deletion by postulating it as just an emergence of the unmarked. However, it could be observed that due to the demand to satisfy the requirement for an open reduplicant for bimorphemic bases is stronger than preserving the reduplicant-final nasal, though opting to preserve the nasal would have been acceptable in the general grammar of the language.

Another possible explanation for the final bilabial nasal deletion is that there is a minimality constraint on the number of morphemes that is allowed in the reduplicants of bimorphemic verb bases. This is what McCarthy and Prince (1994: 2) term "Template Satisfaction". So for all reduplicative prefixes of bimorphemic bases, there should be only one morpheme or one lexical item. Copying the base-final bilabial nasal, the only segmental remnant (the nucleus) of morpheme $e_{2}$ into the reduplicant slot will incur fatal violation of this high-ranking minimality constraint, hence, the deletion of the nasal at the phonetic representation in satisfaction of the high-ranking constraint.

A fourth generalization about this deletion process is that because perhaps the syllabic bilabial nasal lacks a true nucleus as an independent syllable. It therefore becomes vulnerable to deletion. However, it seems after deletion at reduplication, this 'deleted' nasal resurfaces during nominalization of the affected reduplicated verbs as they opt for nasals as their nominal prefixes (instead of the usual low vowel/a-/). This choice is perhaps to compensate for the loss resulting from the reduplication process. This could also be that there is a floating feature '[+nasal]', which surfaces as a nominal prefix in reduplication whenever there is a nasal consonant deletion at the coda of reduplicative prefix.

In the next section, we formalise how verbs with final bilabial nasals of both monomorphemic and bimorphemic bases are reduplicated in Asante.

\section{THE REDUPLICANT-NASAL DELETION FORMALIZED}

The reduplicant-final nasal deletion process is discussed in all the three major dialects of Akan. As has been observed in the data earlier presented in this paper, it is not all base-final bilabial nasals that delete in the reduplicants. The generalisation made about these data is that those base forms that maintain the final nasals in the reduplicants have their final nasals as inherent part of the roots. On the contrary, those base forms that lose their final nasals in the reduplicants are bimorphemic in structure in the underlying representation. The final nasal is actually a separate morpheme on its own, a postposition that has the syllable structure NV in the phonetic representation. The peculiarity of this deletion process stems from the fact that it is neither phonologically-conditioned nor is it morphologically-conditioned in the 
general grammar of Akan. This is so because phonologically, nasals and glides are the only nonvowel segments that can occur in word- final position in the Akan language (Dolphyne, 1988; Abakah, 2005) and morphologically, the morphology of Akan allows closed syllables as reduplicative prefixes as has been exemplified already in (6). So the preference for the open reduplicant (reduplicative prefix) over the closed one it copies from the base is not motivated on any grammatical grounds in the language other than it being treated as an instance of the emergence of the unmarked. This enables the unmarked open syllable to emerge in the reduplicants in this instance.

To account for this phenomenon, this paper postulates minimality requirement, within OT, that is imposed on all reduplicants in Akan that forbids the reduplicants to compose of more than one morpheme or lexical item. Therefore, for verbs that consist of two morphemes i.e. phrasal verb of the composite structure: verb + postposition, only one of them has to be copied to fill the reduplicant template. The choice of which of the two lexical items is copied always falls on the verbs at the expense of the postpositions in reduplication of bimorphemic verb bases in Akan. This analysis, we will later see in the subsequent sections, is superior to rule-based theory; in the sense that with one set of constraints ranking, output forms or candidates that will faithfully copy the entire base will be dispreferred to the ones that copying of only one morpheme (the head) in the reduplicant. Conversely, candidates that partially copy the base - only the head, when reduplicating bimorphemic verbs, emerge as the optimal output forms.

\subsection{OPTIMALITY-THEORETIC ANALYSIS OF AKAN FINAL- NASAL DELETION}

In doing the optimality-theoretic analysis of the different kinds of reduplication data discussed in section 1, we follow McCarthy \& Prince's (1995) Correspondence Theory of reduplication which postulates, as Beckman (1997) expatiates, that there is a wide range of parallels that exist between requirements on base-reduplicant identity in reduplicative morphology on the one hand, and requirements of input-output faithfulness in phonology on the other hand. They further explain the theory as follows.

(12) Correspondence (McCarthy \& Prince, 1995a; Beckman, 1997:13)

Given two related strings $\mathrm{S}_{1}$ and $\mathrm{S}_{2}$ (underlying and surface), correspondence is a relation $\mathscr{R}$ from the elements of $\mathrm{S}_{1}$ to those of $\mathrm{S}_{2}$. An element $\alpha \in \mathrm{S}_{1}$ and any element $\beta \in \mathrm{S}_{2}$ are referred to as CORRESPONDENTS of one another when $\alpha \mathscr{R} \beta$.

We employ constraints from the well-formedness family, as well as the constraints on correspondence from the faithfulness family such as MAX, DEP, and IDENT to analyse the reduplication patterns observed about final nasal consonant deletion in some Akan reduplicants in this paper. This theory, 


\section{VOLUME 8}

THE BUCKINGHAM JOURNAL OF LANGUAGE AND LINGUISTICS

according to Kager (1999), claims that reduplication patterns arise by interactions of this set of constraints. Typological differences and similarities cross-linguistically are captured by the different rankings of constraints from these families of constraints.

We begin our OT analysis by first assuming some constraints from McCarthy and Prince's (1995) correspondence, particularly from the faithfulness family as well as from the markedness family. By ranking the former constraints above the latter, it will ensure that in copying monomorphemic verb bases, no segment is left behind. That is, copying into the reduplicant slot is faithfully done or is complete. The reverse of this ranking will generally produce an output that does not attain a faithful mapping between bases and reduplicants in terms of segmental correspondence, not necessarily featural correspondence, in reduplicating bimorphemic bases. We define our working constraints after McCarthy and Prince, 1995, Kager, 1999, etc. as follows.

The three faithfulness constraints we will employ in our analysis. Two from the correspondence family are MAX-IO and DEP-IO, and from the identity family is IDENT-BR. The constraints are defined as follows;

(13) MAX-IO - Input segments must have output correspondents. (no deletion)

(14) DEP-IO - Output segments must have input correspondents. (no epenthesis)

(15) IDENT-BR - A segment in the base must have a correspondent in the reduplicant.

Two of the markedness constraints used for this analysis include;

$(16) * \mathrm{~V}(+$ low) $\quad$ - Vowels must not be [+low].

$(17)^{*} \mathrm{~V}(+$ high $\left.)\right]_{\mathrm{prWd}}-$ Vowels must not be $[+$ high $]$ at the right edge of a prosodic word (morpheme or lexical word).

The constraint in (17) is a positional neutralisation constraint in that it does not preserve the contrast of feature (in this instance [+high]) between the input and the output. This is so because our input forms, which represent the underlying form always end in a [+high] vowel as we shall see in our succeeding tableaux.

\subsection{ANALYSIS OF REDUPLICATING MONOMORPHEMIC BASES}

In this subsection, I present an OT account of how Akan reduplicates morpheme-final nasal consonants. In the constraints ranking, constraint that demands identity between base and reduplicant is highest ranked due to the fact that reduplication in Akan in general is usually complete. There is usually 
correspondence between the base and the reduplicant in terms of segmental mapping, not necessarily featural mapping due to some phonological processes that the reduplicants undergo such as place assimilation and vowel raising. Let us note that our input forms for the tableaux represent the underlying representation of the bases.

Tableau 1: Analysis of reduplication of an underlying monomorphemic base /pamo/.

\begin{tabular}{|c|c|c|c|c|c|}
\hline /RED-pamo/ 'sew' & DEP-IO & $\begin{array}{c}\text { IDENT- } \\
\text { BR }\end{array}$ & $\begin{array}{c}* \mathrm{~V}(+ \text { high })] \\
\operatorname{PrWd}\end{array}$ & *V(+low $)$ & MAX-IO \\
\hline a. pamv-pamv & & & $* * !$ & $* *$ & \\
\hline b. pam-pam & & & & $* * !$ & $*$ \\
\hline c. pIm-pam & & & & $*$ & $*$ \\
\hline d. pI-pam & & $* !$ & $*$ & $*$ & $*$ \\
\hline e. pIm-pamv & & $* !$ & $*$ & $*$ & \\
\hline
\end{tabular}

(18) The ranking for this tableau: DEP-IO $>>$ IDENT-BR $>>* V(+ \text { high })_{\text {PrWd }}>>$ *V (+low), MAX-IO

In tableau 1, candidates (d) and (e) both fall out of the competition for the optimality due to their fatal violation of the crucially high-ranking faithfulness constraint; IDENT-BR, which requires reduplicants to map onto their bases in terms of segmental match. Both candidates have missed one segment apiece in their reduplicants, thereby making them fatally violate this important identity requirement constraint. The same constraint is also fatally violated by candidate (a) twice by having a high labial vowel at the end of both the base and the reduplicant, though it faithfully reduplicates the base, which in turn faithfully copies the input. The competition therefore, is now between candidate (b), which faithfully copies all segments and features of the base into the reduplicant template, and candidate (c), which reduplicant undergoes vowel raising process. The constraint that decides the optimal output form is *V (+low) that generally prohibits [+low] vowels. Candidate (c) emerges as the optimal because it minimally violates this constraint once while its close competitor, candidate (b) acquires double violation marks for the same constraint. This constraint is not crucially ranked, though, in relation to the least ranked MAX-IO constraint on grounds that re-ranking both constraints does not affect the optimality of candidate (c) in any way, as both candidates additionally violate MAX-IO equally. Let us note that the highest ranking of the constraint DEP-IO will ensure that when the function GEN(erator) generates possibilities such as pım-pım, which would overapply the low 


\section{VOLUME 8}

vowel raising in the reduplicant back to the base, the grammar will eliminate it from ever surfacing.

The analysis in tableau 2 is very akin to what we discussed in tableau 1. The only marked difference between the two is the reduplicant-final nasals of the candidates in the two tableaux.

Tableau 2: Analysis reduplication of monomorphemic bases with final [n].

\begin{tabular}{|l||c|c|c|c|c|}
\hline \hline $\begin{array}{l}\text { /RED-sanI/ } \\
\text { 'to return' }\end{array}$ & $\begin{array}{c}\text { DEP- } \\
\text { IO }\end{array}$ & $\begin{array}{c}\text { IDENT- } \\
\text { BR }\end{array}$ & $* \mathrm{~V}$ (+high)] $\operatorname{PrWd}$ & $* \mathrm{~V}(+$ low $)$ & $\begin{array}{c}\text { MAX- } \\
\text { IO }\end{array}$ \\
\hline \hline a. sanI-sanI & & & $* * !$ & $* *$ & \\
\hline b. san-san & & & & $(* * !)$ & $*$ \\
\hline c. $\sin -$ san & & & & $*$ & $*$ \\
\hline d. sI-san & & $* !$ & $*$ & $*$ & $*$ \\
\hline e. sin-sanI & & $* !$ & $*$ & $*$ & \\
\hline
\end{tabular}

(19) The ranking for this tableau is DEP-IO $>>$ IDENT-BR $>>* V(+$ high $)]_{\text {PrWd }}$ $>$ *V (+low), MAX-IO.

The same ranking of constraints in tableau 2 yields the same output as did by our analysis of tableau 1. It will therefore not be expedient we analyse each candidate again against the same constraint ranking. The optimal candidate (c) in tableau 2 is a direct copy of its counterpart in tableau 1 . We have decided to present tableau 2 with an objective of showing that reduplication of all monomorphemic verbs with final nasals follows the same pattern irrespective of the place of articulation of the final nasal.

\section{ANALYSIS OF REDUPLICATION OF BIMORPHEMIC VERBS}

From our analysis of the data in subsection 1.2, we noticed that the input form for bimorphemic verbs is a composite one i.e. they are of the basic forms such as the verb $(\mathrm{V})+$ the postposition $(m u)$.

By employing the same set of constraints and ranking we used for our analysis in 2.2 for the current bimorphemic base reduplication analysis, we will run into a problem as the analysis will produce a suboptimal candidate as the surface form as we see in tableau 3 below.

In tableau 3, the expected surface form is what we see in candidate (c). However, due to our ranking of the set of constraints, a suboptimal candidate i.e. candidate (d) undesirably emerges as the optimal surface form. To resolve this problem, it would be expedient for our current analysis that we introduce additional structural well-formedness constraint that would ban any candidate such as (a), (d), and (e), that copies more than one lexical item or morpheme into the reduplicant template from emerging as the actual surface form. 
Tableau 3: Analysis of reduplication of bimorphemic base.

\begin{tabular}{|c|c|c|c|c|c|}
\hline $\begin{array}{l}/ \mathrm{RED}-\mathrm{t}^{\mathrm{w}} \mathrm{v}+\mathrm{mu} / \\
\text { 'to close' }\end{array}$ & $\begin{array}{l}\text { DEP- } \\
\text { IO }\end{array}$ & $\begin{array}{l}\text { IDENT- } \\
\text { BR }\end{array}$ & 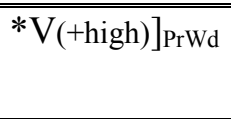 & *V(+low) & $\begin{array}{l}\text { MAX- } \\
\text { IO }\end{array}$ \\
\hline a. $t^{\mathrm{w}} U \cdot \mathrm{mU}-\mathrm{t}^{\mathrm{w}} \mathrm{U} \cdot \mathrm{mu}$ & & & $* * !$ & & \\
\hline b. $t^{w} \mho-t^{w} \mho \cdot m u$ & & $* * !$ & $* *$ & & \\
\hline c. $\mathrm{t}^{\mathrm{w}} \mathrm{U}-\mathrm{t}^{\mathrm{w}} \mathrm{v} \cdot \mathrm{m}$ & & $* !$ & $*$ & & $*$ \\
\hline d. $\gtrsim t^{\mathrm{w}} \mathrm{v} \cdot \mathrm{m}-\mathrm{t}^{\mathrm{w}} \mathrm{U} \cdot \mathrm{m}$ & & & & & * \\
\hline e. $t^{\mathrm{w}} \mathrm{v} \cdot \mathrm{m}-\mathrm{t}^{\mathrm{w}} \mathrm{v} \cdot \mathrm{mu}$ & & $* !$ & * & & \\
\hline
\end{tabular}

To be able to achieve this, that constraint has to outrank the highly-ranked faithfulness constraint IDENT-BR so that its domination will pave way for a structurally obeying candidate to emerge instead of a faithful one. The markedness constraint we will employ in this instance is a template satisfying constraint RED=LEX, which is loosely defined as follows;

(20) $\mathrm{RED}=\mathrm{LEX}$ - A reduplicant should be maximally one lexical item.

Now with this constraint added to the previous set of constraints, let us redo the analysis of bimorphemic verb reduplication we unsuccessfully attempted in tableau 3 as follows in the subsequently tableaux. Tableau 4 presents a reanalysis of tableau 3; therefore, we employ the same set of candidates for tableau 3. The only variation here is the addition of a new constraint without necessarily resorting to re-ranking of the constraints.

Tableau 4: Analysis of reduplication of reduplicant- final nasal deletion in bimorphemic (compounded) bases.

\begin{tabular}{|c|c|c|c|c|c|c|}
\hline $\begin{array}{l}/ \mathrm{RED}-\mathrm{t}^{\mathrm{w}} \mathrm{v}+\mathrm{mu} / \\
\text { 'to close' }\end{array}$ & DEP-IO & RED $=$ LEX & $\begin{array}{c}\text { IDENT- } \\
\text { BR }\end{array}$ & $\begin{array}{c}* \mathrm{~V}(+ \text { high }) \\
] \\
\mathrm{PrWd}\end{array}$ & $\begin{array}{c}* \mathrm{~V}(+\mathrm{low} \\
)\end{array}$ & MAX-IO \\
\hline $\begin{array}{l}\text { a. } \mathrm{t}^{\mathrm{w}} \mathrm{v} \cdot \mathrm{m} v- \\
\mathrm{t}^{\mathrm{w}} \mathrm{v} \cdot \mathrm{mu}\end{array}$ & & $* !$ & & *** & & \\
\hline b. $\mathrm{t}^{\mathrm{w}} \mathrm{v}-\mathrm{t}^{\mathrm{w}} \mathrm{v} \cdot \mathrm{mu}$ & & & $* * !$ & $* *$ & & \\
\hline c. $\mathrm{t}^{\mathrm{w}} U-\mathrm{t}^{\mathrm{w}} \mathrm{U} \cdot \mathrm{m}$ & & & $*$ & $*$ & & $*$ \\
\hline d. $t^{w} \mho \cdot m-t^{w} \mho \cdot m$ & & $* !$ & & & & $*$ \\
\hline e. $t^{w} \mho \cdot m-t^{w} \mho \cdot m u$ & & $* !$ & * & * & & \\
\hline
\end{tabular}




\section{VOLUME 8}

(21) The ranking for the tableau 4: DEP-IO $>>$ RED $=$ LEX $>>$ IDENT-BR $>>$ $* \mathrm{~V}(+ \text { high })_{\mathrm{PrWd}}, * \mathrm{~V}(+$ low $), \mathrm{MAX}-\mathrm{IO}$.

With the introduction and subsequent crucially high ranking of RED=LEX, candidates (a), (d), and (e) are ruled out of the competition for optimality for their violation of constraint RED=LEX. Let us note that equal violation mark is incurred by a candidate for not satisfying this constraint whether a candidate copies the entire morpheme ${ }_{2}$ as done by candidate (a) or it copies additionally, just only the nasal coda of morpheme ${ }_{2}$ as in candidates (d) and (e). Strictly speaking, no segment of morpheme 2 is allowed in the reduplicant. The competition then falls between candidate (b) that faithfully copies the input, but partially reduplicates its base and candidate (c), which on the other hand, partially copies the input, and also like candidate (b), partially reduplicates its base. In this analysis, the decision for the optimality falls on either IDENT-BR, which candidate (c) violates only once vis-à-vis its double violation by candidate (b), or $* \mathrm{~V}(+ \text { high) }]_{\operatorname{PrWd}}$ also for the same reason. As a result, the reranking of these two constraints would not alter the winner of the competition in this tableau analysis. The last two other constraints do not participate in deciding the optimal candidate, hence, they not being ranked in our constraints ranking.

In tableau 5, we employ the same constraints ranking as in (21) to account for another example of reduplication of bimorphemic verbs, but this time the syllable structure of morpheme ${ }_{1}$ being CVV. With the same constraints and ranking and analysis as in tableau 4 , we realised the same result which we expect in the actual form speakers produce.

Tableau 5: Analysis of another reduplicant-final nasal deletion in bimorphemic verb (of CVV morpheme 1 ).

\begin{tabular}{|c|c|c|c|c|c|c|}
\hline $\begin{array}{l}\text { /RED-tij + } \\
\text { mu/ 'to listen } \\
\text { attentively' }\end{array}$ & $\begin{array}{l}\text { DEP- } \\
\text { IO }\end{array}$ & RED $=$ LEX & $\begin{array}{c}\text { IDENT- } \\
\text { BR }\end{array}$ & $\begin{array}{c}\text { *V(+high })] \\
\text { PrWd }\end{array}$ & *V(+low) & $\begin{array}{l}\text { MAX- } \\
\text { IO }\end{array}$ \\
\hline $\begin{array}{l}\text { a. tie.mu- } \\
\text { tiie.mu }\end{array}$ & & $* !$ & & $* *$ & & \\
\hline b. tie-tie.m & & & * & & & * \\
\hline c. tie.m-tie.m & & $* !$ & & & & $*$ \\
\hline d. thie-tie.mu & & & $* * !$ & * & & \\
\hline
\end{tabular}

(22) The ranking for the tableau: DEP-IO $>>$ RED $=$ LEX $>>$ IDENT-BR $>>$ *V(+high) $)_{\mathrm{PrWd}},{ }^{*} \mathrm{~V}(+$ low $)$, MAX-IO. 
Candidate (c) is not technically different from candidate (a) in that, while candidate (a) surfaces with a final high vowel in both the reduplicant and the base, candidate (c), on the other hand, drops the final high vowel in both the base and the reduplicant. The optimal candidate (b) emerges as the eventual winner for the same reason as the optimal candidate in tableau 4.

\section{CONCLUSION}

To conclude, this paper has discussed the exceptional case of reduplicantfinal bilabial nasal deletion we observe in reduplication of some Akan verb bases. We have observed that in reduplicating verb bases that end in bilabial nasals, two surface realisations manifest in the reduplicants: in one instance, the input-final bilabial nasal surfaces in the reduplicant, the base of which we have analysed as monomorphemic. In the other instance, the input-final bilabial nasal is dropped in the reduplicant. This, we have identified and analyzed in this paper that the base of those reduplicants are bimorphemic (phrasal verbs) in composition and that they compose of morpheme ${ }_{1}$ (the verb) and morpheme 2 (the postposition $m u$ ). We observed that the morpheme 2 was virtually always susceptible to elision in the reduplicant and this we attributed to the language's quest to satisfy a high-ranking template satisfaction constraint, within the Optimality Theory, that demands only one lexical item to fill the reduplicant template always. The decision to sacrifice the postposition i.e. morpheme ${ }_{2}$ instead of the head of the encliticised phrasal verb base i.e. morpheme ${ }_{1}$ might have resulted from preservation of the unmarked item as the head is less marked than the affix, which in our case is the postposition.

There have been diverse explanations for similar deletion process observed in other languages and one of such explanations comes from Pater (1999) who explains such a phenomenon as a contextual nasal deletion, which he argues to be one of the ways to prevent the sequence of nasal and voiceless obstruent (*NÇ). Contrary to Pater's argument, there are forms like kĩn-kãn 'read repeatedly', tĩñn-tiãm 'pick up continuously', etc. that permit interaction of nasals and following voiceless obstruents in Akan verbal reduplication. Unlike in the Astronesian language where sequence of nasal and voiceless obstruent is prohibited, Akan rather prefers this sequence in the surface representation to nasal + voiced obstruent sequence where in the latter case place assimilation is very likely to result.

To further throw light on the issue of what actually constitute the underlying representation of bimorphemic base forms, I will recommend a morphosyntactic analysis in the future to comprehensively account for their actual composition. Again, the study, to some extent, has sought to account for mitigating the challenge a first language acquirer or a second language learner might encounter in acquiring the morphophonology of Akan, 


\section{VOLUME 8}

THE BUCKINGHAM JOURNAL OF LANGUAGE AND LINGUISTICS

particularly in reduplication of some verbal base forms that manifest final nasals in the surface representation of Akan grammar.

\section{REFERENCES}

Abakah, E.N. 2005. Phonological analysis of word-final consonants in Akan.

Africa and Asia, No 5, 47-65.

- . 2004. Elision in Fante. Africa \& Asia, No 4, 181-213.

- . 2015. On tone and morphophonology of the Akan reduplication construction. Journal of Universal Language, 16(1), 1-47.

Adomako, K. 2012. Vowel raising in Akan reduplication. Legon Journal of Humanities, 23, 155-184.

Beckman, J. N. 1997. Positional faithfulness, positional neutralisation and Shona vowel harmony. Phonology 14, 1-46. CUP.

Christaller, J.G.1875 [1964]. A Grammar of the Asante and Fante Language, called Tshi [Chee,Twi]: based on the Akuapem Dialect with Reference to the other (Akan and Fante) Dialects, Basel: Basel Evangelical Missionary Society. [Reproduced Farnborough, Hants., England: Gregg Press].

Dolphyne, F.A. 1988. The Akan (Fante-Twi) language: Its sound system and tonal structure. Accra: Universities of Ghana Press.

Eshun, F.B. 1993. Aspects of Akan Phonology. PhD Thesis, University of WisconsinMadison.

Kager, R. 1999. Optimality Theory. Cambridge textbooks in linguistics. Cambridge: CUP.

Marantz, A. 1982. Re Reduplication. Linguistic Inquiry 13, 483-545.

McCarthy, J. and Alan Prince, 1994. Emergence of the Unmarked: Optimality in Prosodic Morphology. In M. Gonzàlez (ed), Proceedings of the North East Linguistic Society, 24. 333-79.

- . 1995. Faithfulness and reduplicative identity. In Jill Beckman, Suzzane Urbanczyk and Laura Walsh-Dickey (eds.), University of Massachusetts Occasional Papers in Linguistics 18: Papers in Optimality Theory, 249-384. Amherst: UMass.

- .1997. Faithfulness and identity in Prosodic Morphology. Ms. University of Massachusetts, Amherst and Rutgers University, New Brunswick. ROA 216.

Ofori, S. A. 2013. A prosodic analysis of monosyllabic and disyllabic verb reduplication in Twi (Akan). Journal of African Languages and Linguistics, 34 (1), 75-109.

Pater, J. 1999. Austronesian Nasal Substitution and other NC effects. In R. Kager, H.Van der Hulst and W. Zonneveld (eds), 310-343. Cambridge: CUP.

Raimy, E. 2000. The Phonology and Morphology of Reduplication. Studies in

Generative Grammar 52. Berlin; New York: Mouton de Gruyter.

Schachter, P. \& Victoria Fromkin. 1968. A Phonology of Akan: Akuapem,

Asante \& Fante. UCLA Working papers in Phonetics, n9. University of California, Los Angeles (UCLA).

Welmers, W.E. 1946. A Descriptive Grammar of Fanti. Language Dissertation 39. (Language vol. 22, no.3 Suppl.). 
Wilbur, R. 1973a. The Phonology of Reduplication. Doctoral dissertation. University of Illinois, Urbana-Champaign.

- $\quad .1973 b$. Reduplication and rule ordering. In Papers from the Ninth Regional

Meeting of the Chicago Linguistic Society. Chicago: Chicago Linguistic Society. Pp 679-687.

- $.1973 \mathrm{c}$. The identity constraint: An explanation for the irregular behaviour of some exceptional reduplicated forms. Studies in the Linguistic Sciences 3 (1), 143-154. 